\title{
Incidences and factors associated with perioperative cardiac arrest in trauma patients receiving anesthesia
}

This article was published in the following Dove Press journal: Risk Management and Healthcare Policy

\author{
Visith Siriphuwanun' \\ Yodying Punjasawadwong' \\ Suwinai Saengyo ${ }^{2}$ \\ Kittipan Rerkasem ${ }^{2,3}$ \\ 'Department of Anesthesiology, \\ Faculty of Medicine, Chiang Mai \\ University, Chiang Mai, Thailand; \\ ${ }^{2}$ Non-communicable Disease Center \\ of Excellence and Department of \\ Surgery, Faculty of Medicine, Chiang \\ Mai University, Chiang Mai, Thailand; \\ ${ }^{3}$ Non-communicable Disease Center \\ of Excellence, Research Institute \\ for Health Sciences, Chiang Mai \\ University, Chiang Mai, Thailand
}

Purpose: The aim of this study was to determine the incidences and factors associated with perioperative cardiac arrest in trauma patients who received anesthesia for emergency surgery. Patients and methods: This retrospective cohort study was approved by the medical ethical committee, Faculty of Medicine, Maharaj Nakorn Chiang Mai Hospital, Thailand. Data of 19,683 trauma patients who received anesthesia between January 2007 and December 2016, such as patient characteristics, surgery procedures, anesthesia information, anesthetic drugs, and cardiac arrest outcomes, were analyzed. Data of patients receiving local anesthesia by surgeons or monitoring anesthesia care (MAC) and those with much information missing were excluded. Factors associated with perioperative cardiac arrest were identified using univariate analysis and the multiple regression model. A stepwise algorithm was chosen at a $P$-value of $<0.20$ which was selected for multivariate analysis. A $P$-value of $<0.05$ was concluded as statistically significant. Results: The perioperative cardiac arrest in trauma patients receiving anesthesia for emergency surgery was 170.04 per 10,000 cases. Factors associated with perioperative cardiac arrest in trauma patients were as follows: age $>65$ years (risk ratio $[\mathrm{RR}]=1.41, \mathrm{CI}=1.02-1.96, P=0.039$ ), American Society of Anesthesiologist (ASA) physical status 3 or higher (ASA physical status 3-4, RR =4.19, CI =2.09-8.38, $P<0.001$; ASA physical status 5-6, $\mathrm{RR}=21.58, \mathrm{CI}=10.36-44.94$, $P<0.001$ ), sites of surgery (intracranial, intrathoracic, upper intra-abdominal, and major vascular, each $P<0.001$ ), cardiopulmonary comorbidities ( $R R=1.55, \mathrm{CI}=1.10-2.17, P=0.012$ ), hemodynamic instability with shock prior to receiving anesthesia $(\mathrm{RR}=1.60, \mathrm{CI}=1.21-2.11, P<0.001)$, and having a history of alcoholism $(\mathrm{RR}=5.27, \mathrm{CI}=4.09-6.79, P<0.001)$.

Conclusion: The incidence of perioperative cardiac arrest in trauma patients receiving anesthesia for emergency surgery was very high and correlated with patient's factors, especially old age and cardiopulmonary comorbidities, a history of drinking alcohol, increased ASA physical status, hemodynamic instability with shock prior to surgery, and sites of surgery such as brain, thorax, abdomen, and the major vascular region. Anesthesiologists and surgeons should be aware of a warning system and a well-equipped track to manage the surgical trauma patients.

Keywords: anesthesia, emergency surgery, incidence, perioperative cardiac arrest, risk factor, trauma patients, cardiac arrest in trauma patients receiving anesthesia

\section{Introduction}

The number of trauma patients receiving anesthesia for emergency surgery is higher in developing countries than in developed countries. ${ }^{1-4}$ These patients have increased risk of intraoperative cardiac arrest, ${ }^{2,4-6}$ over two times higher than that in elective surgical patients with high mortality rates. ${ }^{4,5,7-12}$ Studies conducted in countries, in the past decade, such as Brazil showed that more than $50 \%$ of all incidences of perioperative 
cardiac arrest in surgical patients occurred in trauma patients receiving emergency surgeries. ${ }^{10}$ Furthermore, five studies that were conducted between 2012 and 2016 reported that the maximum number of incidences of cardiac arrest in trauma patients occurred in road traffic accidents..$^{5,11,13-16}$ In Asian countries, incidences of all perioperative cardiac arrest vary in the range of $3-40$ per 10,$000 ;{ }^{17-20}$ there is an increase in the number of emergency surgeries compared to the number of incidences varying in the range of 7-160 per 10,000, and it is very high in trauma patients who experienced traffic accidents. ${ }^{2,18}$ It was reported that in northern Thailand, among patients who underwent emergency surgery, there were high incidence rates of cardiac arrest within 24 hours of anesthesia and that these rates were higher than those in other Thailand regions and other countries. ${ }^{2}$

Depending on the type and severity of injuries, organ damage and high risk of cardiac arrest and death can occur; the injuries include vascular injuries, ${ }^{21}$ blunt traumatic cardiac injuries, ${ }^{22}$ gunshot wounds and stab wounds, ${ }^{23}$ and multiple injuries. ${ }^{10}$ Other studies have reported the types of accidents such as falling from a height and road traffic accidents that involve many organ injuries including head injury, injury of the lower extremities, and thoracic injury. ${ }^{6}$

High-risk trauma patients undergoing emergency surgery have several risks, especially risks that are unplanned, including receiving anesthesia, surgery, unplanned admittance to the intensive care unit (ICU), and those related to limited preoperative anesthetic preparation. ${ }^{24}$ Furthermore, there are many high-risk factors that increase the incidence rate of cardiac arrest, including massive blood loss and multiple fractures or injuries to various organs of the patient and the patient having very high complications with regard to difficult airway management. ${ }^{1,21}$ In accident situations, trauma patients are often treated improperly prior to receiving anesthesia for emergency surgery during both regular hours and after hours. Furthermore, in trauma patients, it has been observed that uncontrolled bleeding occurs in approximately $40-60 \%$ of intraoperative cardiac arrests and deaths. ${ }^{25}$

As reported in previous studies, ${ }^{20,21,26}$ it has been found that many factors are associated with perioperative cardiac arrest, including age, ${ }^{20,26}$ underlying diseases, ${ }^{2,4}$ American Society of Anesthesiologist (ASA) physical status, ${ }^{2,8,9}$ blood loss,${ }^{3}$ the anatomic site of surgery, ${ }^{20,27}$ and severity of injury (especially blunt trauma with multiple injuries and vascular injuries). ${ }^{10,12,21}$ Warning of such risk factors would be of help to anesthesia providers to plan appropriate anesthetic care and prepare drugs and resuscitating equipment to promptly deal with cardiac arrest and also create a warning sign tool for detecting signs of cardiac arrest in high-risk patients. However, few studies have elucidated incidences and factors associated with perioperative cardiac arrest in trauma patients receiving anesthesia. ${ }^{2,10}$ The number of accident victims undergoing emergency surgery is very likely to increase due to population growth over the next decade, and the mortality rate is expected to be high. ${ }^{5}$ Hence, it is a challenge to formulate a strength strategy that includes administration of anesthesia, cardiopulmonary resuscitation (CPR) guidelines for perioperative cardiac arrest, and surgical treatment suitable for these patients. ${ }^{22}$

Therefore, this study was conducted to throw light on the incidences and factors associated with trauma patients who suffered cardiac arrest during the intraoperative period after receiving anesthesia, at Maharaj Nakorn Chiang Mai Hospital, a university-based teaching hospital in northern Thailand.

\section{Patients and methods}

Our retrospective study was scrutinized and approved by the medical ethical committee of the Faculty of Medicine at Maharaj Nakorn Chiang Mai Hospital without requiring consent from patients, because this study was low risk and we collected data as anonymous. In addition, the result could not link to any particular patients. Furthermore, all data were collected confidentially and only a limited number of researchers could access the data obtained. Database of 19,683 trauma patients who received anesthesia for an emergency surgery in the past decade, from January 1, 2007, to December 31, 2016, was reviewed.

The recorded data were documented from the start of anesthesia until the end of anesthesia by using a study recording form, ${ }^{2}$ which was approved for content validity by experienced anesthesiologists. The method of collecting data was tested by recording information from ten cases of trauma patients who received anesthesia for emergency surgery before being used in the researchers' center.

The detailed data consisted of patient characteristics including age, sex, medication use or substance abuse, and patient's comorbidities. Additional information included the assessment of the physical condition of the patient before anesthesia, the anatomic site of surgery, anesthesia performed, classification of the ASA physical status, patient monitoring, airway management, anesthetic drugs, and outcomes after anesthesia.

Details of the event were recorded in the data-recording form and checked for accuracy before entering the same into the anesthesia database. In addition, the completed data were obtained by chart review and from the digital hospital 
database of medical records, anesthesiology records, electrocardiogram, and laboratory reports. Data extraction from the database for analyses was done by two research assistants who were trained and tested for standardized data collection under anesthesiologists to ensure accuracy of information. All the data entered for this analysis were tested for accuracy by using the double entry technique. Data regarding patients who had received topical anesthesia by surgeons, patients undergoing monitoring anesthesia care (MAC), and patients on whom much information was missing were excluded from this study.

Cardiac arrest in trauma patients in this study was defined as a sudden state of circulatory failure due to loss of cardiac systolic function; changing specific cardiac rhythm disturbances of the heart before the occurrence of cardiac arrest including ventricular fibrillation (VF), pulseless ventricular tachycardia (VT), pulseless electrical activity (PEA), and asystole; and the occurrence of these events during anesthesia of trauma surgical patients.

\section{Statistical analyses}

Statistical analyses were performed using the STATA (StataCorp LP, College Station, TX, USA). Descriptive statistics were used to analyze the characteristic variables, including sex, age, ASA physical status, current drugs, comorbidities, and personal history. The chi-squared test or Fisher's exact statistic was used to analyze the categorical variables, and the independent $t$-test or the Wilcoxon's rank-sum test was used to analyze the continuous data. The variables potentially correlated with cardiac arrest were clarified by using the univariable statistical analysis. The factors associated with perioperative cardiac arrest in trauma patients at $P$-value of $<0.20$ were selected for multivariate analysis by a stepwise multivariable generalized linear regression for risk ratio (RR). The multicollinearity of all the variables was examined by bivariate correlation matrix. If any factors showed multicollinearity, only one of them was selected to further multivariate analysis. A $P$-value of $<0.05$ was concluded as statistically significant. The RR and the $95 \%$ CI were used to summarize the significant factors associated with cardiac arrest.

\section{Results}

During the period of a decade, perioperative cardiac arrest during anesthesia for trauma patients occurred in 332 cases out of 19,683 trauma surgical patients $(170.04: 10,000)$. Most of the trauma patients were male $(72.2 \%)$, and their age ranged from 6 to 98 years. Most of them had received general anesthesia (GA) and belonged to ASA physical status class $\geq 3$ (47.8\%). The characteristics of these patients were compared regard- ing distribution of preoperative comorbidity, anatomic sites of surgery, personal history, and substance abuse between the groups with and without intraoperative cardiac arrest. Patients in both groups were statistically different in many variables, as summarized in Table 1. The performance of anesthetics including anesthetic agents is presented in Tables 2 and 3. There were significant differences in the average duration of anesthesia between the two groups (100.8 $\pm 82.5 \mathrm{vs}$ $139.7 \pm 106.2$ minutes). The conditions of the trauma patients prior to receiving anesthesia, including hemodynamic conditions, respiratory conditions, and neuromuscular conditions, are summarized in Table 2. In the univariate analysis, many factors are presented, which are statistically significant factors, such as age $>65$ years $(\mathrm{RR}=1.78, \mathrm{CI}=1.29-2.44)$, ASA physical status class $\geq 3$, anatomic sites of surgery (especially, upper intra-abdomen, intracranial, intrathoracic, cardiac, and major vascular), the patient's comorbidity (especially, cardiopulmonary status, neuromuscular condition, hematology, electrolyte imbalance, and miscellaneous), personal history that involves drinking alcohol $(\mathrm{RR}=13.44, \mathrm{CI}=10.83-16.68)$, hemodynamic instability with shock prior to receiving anesthesia ( $R R=23.23, C I=20.07-26.87)$, respiratory conditions with regard to the endotracheal tube from the emergency room $(\mathrm{ER}) / \mathrm{ICU} /$ ward prior to surgery $(\mathrm{RR}=3.52, \mathrm{CI}=2.02-6.13)$, etc., which are summarized in Tables 2 and 3.

In this study, multivariate analysis of data was conducted such as age $>65$ years $(\mathrm{RR}=1.41, \mathrm{CI}=1.02-1.96, P=0.039)$, ASA physical status $\geq 3$ (ASA physical status 3-4, RR $=4.19$, $\mathrm{CI}=2.09-8.38, P<0.001$; ASA physical status 5-6, RR $=21.58, \mathrm{CI}=10.36-44.94, P<0.001)$, anatomic sites of surgery (intracranial, intrathoracic, upper intra-abdominal, and major vascular, each $P<0.001$ ), cardiopulmonary comorbidity ( $\mathrm{RR}=1.55, \mathrm{CI}=1.10-2.17, P=0.012)$, patients having hemodynamic instability with shock prior to receiving anesthesia $(\mathrm{RR}=1.60, \mathrm{CI}=1.21-2.11, P<0.001)$, and personal history that involved drinking alcohol $(\mathrm{RR}=5.27, \mathrm{CI}=4.09-6.79$, $P<0.001)$, which are significant factors associated with perioperative cardiac arrest in trauma patients receiving anesthesia for emergency surgery (Table 4).

\section{Discussion}

Trauma patients receiving anesthesia for emergency surgery were found to be not well prepared to undergo unplanned anesthesia, and among them, some had had severe blood loss or damage to vital organs, leading to massive perioperative cardiac arrest and death. ${ }^{3,8,17,18,20}$ However, many studies did not clarify the risk factors associated with only perioperative cardiac arrest in trauma patients..$^{2,28-30}$ 
Table I Baseline characteristics of trauma patients receiving anesthesia for emergency surgery

\begin{tabular}{|c|c|c|c|c|c|}
\hline \multirow[t]{2}{*}{$\begin{array}{l}\text { Baseline characteristic of } \\
\text { trauma patients }\end{array}$} & \multicolumn{2}{|c|}{$\begin{array}{l}\text { Perioperative cardiac arrest in } \\
\text { trauma patients }\end{array}$} & \multirow[t]{2}{*}{$\begin{array}{l}\text { Univariable } \\
\text { RR }\end{array}$} & \multirow[t]{2}{*}{$95 \% \mathrm{Cl}$} & \multirow[t]{2}{*}{$P$-value } \\
\hline & Yes (n=332), n (\%) & No $(n=19,35 I), n(\%)$ & & & \\
\hline \multicolumn{6}{|c|}{ ( } \\
\hline Female & $83(25.0)$ & $5,385(27.8)$ & 1.00 & & \\
\hline Male & $249(75.0)$ & $13,966(72.2)$ & 1.15 & $0.90-1.48$ & 0.258 \\
\hline \multicolumn{6}{|l|}{ Age (years) } \\
\hline$\leq 12$ & $27(8.1)$ & $1,569(8.1)$ & 1.27 & $0.83-1.96$ & 0.258 \\
\hline $13-34$ & $97(29.2)$ & $7,237(37.4)$ & 1.00 & & \\
\hline $35-65$ & $144(43.4)$ & $7,889(40.8)$ & 1.33 & $1.03-1.73$ & 0.028 \\
\hline$>65$ & $64(19.3)$ & $2,656(13.7)$ & 1.79 & $1.32-2.44$ & $<0.001$ \\
\hline Mean \pm SD & $42.3 \pm 22.9$ & $39.3 \pm 21.4$ & 1.01 & $1.00-1.02$ & 0.011 \\
\hline BMI $\left(\mathrm{kg} / \mathrm{m}^{2}\right)$, mean $\pm \mathrm{SD}, \mathrm{n}=12,622$ & $22.2 \pm 4.5$ & $21.9 \pm 3.5$ & 1.01 & $0.95-1.072$ & 0.739 \\
\hline \multicolumn{6}{|l|}{ ASA physical status } \\
\hline $\mathrm{I}-2$ & II (3.3) & $10,268(53.1)$ & 1.00 & & \\
\hline $3-4$ & $98(29.5)$ & $8,515(44.0)$ & 10.63 & $5.70-19.29$ & $<0.001$ \\
\hline $5-6$ & $223(67.2)$ & $568(2.9)$ & 263.44 & $|34.8|-482.59$ & $<0.001$ \\
\hline \multicolumn{6}{|l|}{ Anatomic site of surgery } \\
\hline Maxillofacial & $2(7.2)$ & $\mathrm{I}, 033(5.3)$ & 0.11 & $0.03-0.43$ & $<0.001$ \\
\hline ENT & II (3.3) & $2,168(\mid I .2)$ & 1.08 & $0.59-1.97$ & 0.792 \\
\hline Lower intra-abdominal & $5(1.5)$ & $1,260(6.5)$ & 0.22 & $0.09-0.54$ & $<0.001$ \\
\hline Upper intra-abdominal & $152(45.8)$ & I,657 (8.6) & 8.34 & $6.72-10.35$ & $<0.001$ \\
\hline Intracranial & $7 \mid(2 I .4)$ & $3,354(17.33)$ & 1.29 & $1.01-1.7$ & 0.034 \\
\hline Intrathoracic & $46(13.9)$ & $598(3.1)$ & 4.8 & $3.48-6.49$ & $<0.001$ \\
\hline Cardiac & $19(5.7)$ & $254(1.3)$ & 4.3 & $2.72-6.86$ & $<0.001$ \\
\hline Major vascular & $14(4.2)$ & $232(1.2)$ & 4.56 & $2.03-5.94$ & $<0.001$ \\
\hline Extremities & $13(3.9)$ & $8,255(42.7)$ & 0.06 & $0.032-0.09$ & $<0.001$ \\
\hline \multicolumn{6}{|l|}{ Patients' comorbidity ${ }^{\mathrm{a}}$} \\
\hline Cardiopulmonary & $281(84.6)$ & $5,537(28.6)$ & 13.13 & $9.74-17.69$ & $<0.001$ \\
\hline Neuromuscular & $108(32.5)$ & $3,286(16.9)$ & 2.31 & $|.83-2.9|$ & $<0.001$ \\
\hline Hematological & $175(52.7)$ & $4,328(22.4)$ & 3.76 & $3.02-4.66$ & $<0.001$ \\
\hline Endocrine & $43(12.9)$ & $1,927(9.9)$ & 1.34 & $0.97-1.84$ & 0.075 \\
\hline Electrolyte imbalance & $29(8.7)$ & $826(4.3)$ & 2.11 & $1.44-3.08$ & $<0.001$ \\
\hline Miscellaneous $^{\mathrm{b}}$ & $175(52.7)$ & $5,604(28.9)$ & 2.68 & $2.16-3.33$ & $<0.001$ \\
\hline \multicolumn{6}{|l|}{ Personal history } \\
\hline Previous anesthesia & $104(31.3)$ & $5,835(30.2)$ & 1.06 & $0.84-1.33$ & 0.647 \\
\hline Smoking $\geq 10$ packets per year & $7(2.1)$ & $861(4.5)$ & 0.47 & $0.22-0.99$ & 0.046 \\
\hline Alcoholic & $152(45.8)$ & $1,011(5.2)$ & 13.44 & $10.83-16.68$ & $<0.001$ \\
\hline Allergy history & $\mathrm{I}(0.1)$ & $211(1.1)$ & 0.27 & $0.04-1.92$ & 0.191 \\
\hline \multicolumn{6}{|l|}{ Anesthesia technique } \\
\hline Non-GA & $\mathrm{I}(0.3)$ & $3,347(17.3)$ & 1.00 & & \\
\hline GA & $313(94.3)$ & $14,934(77.2)$ & 68.72 & $9.65-489.39$ & $<0.001$ \\
\hline GA (TIVA) & $18(5.4)$ & $1,070(5.5)$ & 55.38 & $7.39-414.86$ & $<0.001$ \\
\hline \multicolumn{6}{|l|}{ Airway management } \\
\hline On endotracheal tube & $315(94.9)$ & $14,919(77.1)$ & $5.4 I$ & $3.32-8.82$ & $<0.001$ \\
\hline Tracheostomy & $2(0.6)$ & $345(1.8)$ & 0.34 & $0.08-1.35$ & 0.126 \\
\hline Double lumen tube & $6(1.8)$ & $208(1.1)$ & 1.67 & $0.75-3.75$ & 0.211 \\
\hline Bronchoscope & $2(0.6)$ & II (0.I) & 9.17 & $2.28-36.82$ & 0.002 \\
\hline Others & $17(5.1)$ & $44(0.2)$ & 17.36 & $10.65-28.28$ & $<0.001$ \\
\hline \multicolumn{6}{|l|}{ Time of receiving anesthesia } \\
\hline Working hours & $75(22.6)$ & $6,922(35.8)$ & 1.00 & & \\
\hline Nonworking hours & $257(77.4)$ & $12,429(64.2)$ & 1.89 & $1.46-2.44$ & $<0.001$ \\
\hline Duration of anesthesia, mean \pm SD & $100.8 \pm 82.5$ & $139.7 \pm 106.2$ & 0.99 & $0.99-1.00$ & $<0.001$ \\
\hline Intensive monitoring & $182(54.8)$ & $5,873(30.4)$ & 2.73 & $2.20-3.38$ & $<0.001$ \\
\hline
\end{tabular}

Notes: aThe patient's comorbidity in this study was more than one comorbidity. 'Miscellaneous: disease in this finding was sepsis, renal impairment, autoimmune disease, liver disease (cirrhosis, abnormal LFT, jaundice), ascites, fever, and morbid obesity.

Abbreviations: ASA, American Society of Anesthesiologist; ENT, ear, nose, throat; GA, general anesthesia; LFT, liver function test; RR, risk ratio; TIVA, total intravenous anesthesia. 
Table 2 Hemodynamic, respiratory, and neuromuscular conditions of trauma patients prior to receiving anesthesia for emergency surgery

\begin{tabular}{|c|c|c|c|c|c|}
\hline \multirow[t]{2}{*}{$\begin{array}{l}\text { Condition of trauma patients } \\
\text { prior to receiving anesthesia }\end{array}$} & \multicolumn{2}{|c|}{$\begin{array}{l}\text { Perioperative cardiac arrest } \\
\text { in trauma patients }\end{array}$} & \multirow[t]{2}{*}{$\begin{array}{l}\text { Univariable } \\
\text { RR }\end{array}$} & \multirow[t]{2}{*}{$95 \% \mathrm{Cl}$} & \multirow[t]{2}{*}{$P$-value } \\
\hline & Yes $(n=332), n(\%)$ & No $(n=19,35 I), n(\%)$ & & & \\
\hline \multicolumn{6}{|c|}{ Hemodynamic condition of patients prior to surgery } \\
\hline Shock/impending shock & $34 I(47.3)$ & $\mathrm{I}, 308(3.0)$ & 23.23 & $20.07-26.87$ & $<0.001$ \\
\hline Post-cardiac arrest & $69(20.8)$ & $47(0.2)$ & 44.25 & $33.94-57.68$ & $<0.001$ \\
\hline Arrhythmias & $17(5.1)$ & $429(2.2)$ & 2.32 & $1.42-3.79$ & 0.001 \\
\hline Hypertension & $25(7.5)$ & $2,356(12.2)$ & 0.59 & $0.39-0.89$ & 0.012 \\
\hline \multicolumn{6}{|c|}{ Respiratory condition of patients prior to surgery } \\
\hline On endotracheal tube from ER/ICU/ward & $265(79.8)$ & $4,242(21.9)$ & 3.52 & $2.02-6.13$ & $<0.001$ \\
\hline $\mathrm{SpO}_{2}<90 \%$ & $15(4.5)$ & $211(1.1)$ & 4.07 & $2.43-6.83$ & $<0.001$ \\
\hline Respiratory failure & $7(2.1)$ & $102(0.5)$ & 3.87 & $1.83-8.18$ & $<0.001$ \\
\hline \multicolumn{6}{|c|}{ Neuromuscular condition of patients prior to surgery } \\
\hline Alteration in consciousness & $85(25.6)$ & $2,892(14.9)$ & 1.93 & $1.5 \mathrm{I}-2.47$ & $<0.001$ \\
\hline Previous CVA/TIA & $4(1.2)$ & $263(1.4)$ & 0.89 & $0.33-2.37$ & 0.811 \\
\hline Spinal cord injury & $2(0.6)$ & $163(0.8)$ & 0.72 & $0.18-2.87$ & 0.639 \\
\hline Neuropathy/myopathy & $4(1.2)$ & $221(1.2)$ & 1.05 & $0.39-2.83$ & 0.916 \\
\hline Increase in ICP & $38(11.5)$ & $2,691(13.9)$ & 0.80 & $0.57-1.12$ & 0.203 \\
\hline Convulsion & $\mathrm{I}(0.3)$ & $100(0.5)$ & 0.59 & $0.08-4.17$ & 0.593 \\
\hline Others & $19(5.7)$ & $869(4.5)$ & 1.28 & $0.8 I-2.04$ & 0.289 \\
\hline
\end{tabular}

Abbreviations: CVA, cerebrovascular accident; ER, emergency room; ICP, intracranial pressure; ICU, intensive care unit; RR, risk ratio; TIA, transient ischemic attack.

Table 3 Anesthetic agents used in trauma patients receiving anesthesia for emergency surgery

\begin{tabular}{|c|c|c|c|c|c|}
\hline \multirow[t]{2}{*}{ Characteristics } & \multicolumn{2}{|c|}{ Perioperative cardiac arrest } & \multirow[t]{2}{*}{ Univariable RR } & \multirow[t]{2}{*}{$95 \% \mathrm{Cl}$} & \multirow[t]{2}{*}{$P$-value } \\
\hline & Yes, n (\%) & No, n (\%) & & & \\
\hline Pentothal & $35(10.5)$ & $9,337(48.3)$ & 0.13 & $0.09-0.18$ & $<0.001$ \\
\hline Propofol & $32(9.6)$ & $4,430(22.9)$ & 0.36 & $0.25-0.52$ & $<0.001$ \\
\hline Ketamine & $40(12.1)$ & $519(2.7)$ & 4.67 & $3.37-6.52$ & $<0.001$ \\
\hline Etomidate & $21(6.33)$ & $936(4.8)$ & 1.32 & $0.85-2.06$ & 0.217 \\
\hline Midazolam & $210(63.3)$ & $5,198(26.9)$ & 4.54 & $3.63-5.68$ & $<0.001$ \\
\hline Diazepam & $4(1.2)$ & $465(2.4)$ & 0.49 & $0.19-1.34$ & 0.168 \\
\hline Nitrous oxide & $21(6.3)$ & $9,155(47.3)$ & 0.08 & $0.05-0.12$ & $<0.001$ \\
\hline Halothane & $2(0.6)$ & $2,279(11.8)$ & 0.05 & $0.01-0.18$ & $<0.001$ \\
\hline Isoflurane & $39(11.8)$ & $6,648(34.4)$ & 0.26 & $0.19-0.36$ & $<0.001$ \\
\hline Sevoflurane & $63(18.9)$ & $5,899(30.5)$ & 0.54 & $0.4 I-0.70$ & $<0.001$ \\
\hline Desflurane & $2(0.6)$ & $61(0.3)$ & 1.89 & $0.47-7.58$ & 0.370 \\
\hline Succinylcholine & $19(5.7)$ & 4,75 I (24.6) & 0.19 & $0.12-0.30$ & $<0.001$ \\
\hline Pancuronium & $72(21.7)$ & 4,43 I (22.9) & 0.93 & $0.72-1.21$ & 0.606 \\
\hline Atracurium & $27(8.1)$ & $3,964(20.5)$ & 0.35 & $0.23-0.51$ & $<0.001$ \\
\hline Cisatracurium & $88(26.5)$ & $2,382(12.3)$ & 2.51 & $1.97-3.20$ & $<0.001$ \\
\hline Vecuronium & $59(17.8)$ & 3,817 (19.7) & 0.88 & $0.67-1.16$ & 0.379 \\
\hline Rocuronium & $3(0.9)$ & $740(3.8)$ & 0.23 & $0.07-0.72$ & 0.012 \\
\hline Morphine & $4(1.2)$ & $2,532(13.1)$ & 0.08 & $0.03-0.22$ & $<0.001$ \\
\hline Fentanyl & $211(63.6)$ & 14,068 (72.7) & 0.66 & $0.53-0.82$ & $<0.001$ \\
\hline
\end{tabular}

Abbreviation: RR, risk ratio.

This study analyzed the anesthetic database of trauma patients receiving anesthesia for emergency surgery in the past decade at Maharaj Nakorn Chiang Mai Hospital, northern Thailand. The study was conducted in a total of 19,685 cases, and the rate of incidence of perioperative cardiac arrest was 170.04 per 10,000 cases, which is high and similar to the findings of a study in Thailand and another study in
USA. ${ }^{1,3}$ Additionally, the present study showed a higher rate of incidence of cardiac arrest than studies in patients who had undergone elective surgery, emergency surgery in the present study's setting, and in a Thai study $(8.5$ per 10,000 cases, 163 per 10,000 cases, and 30.8 per 10,000 cases, respectively). ${ }^{2,31}$ Compared to five other studies conducted in Thailand, this study's rate of incidence of cardiac arrest 
Table 4 Factors associated with perioperative cardiac arrest in trauma patients receiving anesthesia for emergency surgery

\begin{tabular}{|c|c|c|c|}
\hline Factors & Multivariable RR & $95 \% \mathrm{Cl}$ & $P$-value \\
\hline \multicolumn{4}{|l|}{ Age (years) } \\
\hline$\leq 12$ & 1.77 & $0.97-3.25$ & 0.064 \\
\hline $13-34$ & 1.00 & & \\
\hline $35-64$ & 1.02 & $0.78-1.32$ & 0.910 \\
\hline$>65$ & 1.41 & $1.02-1.96$ & 0.039 \\
\hline \multicolumn{4}{|l|}{ ASA physical status } \\
\hline $\mathrm{I}-2$ & 1.00 & & \\
\hline $3-4$ & 4.19 & $2.09-8.38$ & $<0.001$ \\
\hline $5-6$ & 21.58 & $10.36-44.94$ & $<0.001$ \\
\hline \multicolumn{4}{|l|}{ Anatomic site of surgery } \\
\hline Intracranial surgery & 2.11 & $1.46-3.05$ & $<0.001$ \\
\hline Upper intra-abdominal surgery & 1.92 & $1.36-2.70$ & $<0.001$ \\
\hline Intrathoracic surgery & 1.84 & $1.20-2.80$ & 0.005 \\
\hline Major vascular surgery & 1.87 & $1.10-3.47$ & 0.049 \\
\hline Preoperative cardiopulmonary comorbidity & 1.55 & $1.10-2.17$ & 0.012 \\
\hline \multicolumn{4}{|l|}{ Personal history } \\
\hline Alcoholic & 5.27 & $4.09-6.79$ & $<0.001$ \\
\hline \multicolumn{4}{|c|}{ Hemodynamic condition prior to receiving anesthesia } \\
\hline Shock before receiving anesthesia & 1.60 & $1.21-2.11$ & 0.001 \\
\hline
\end{tabular}

Abbreviations: ASA, American Society of Anesthesiologist; RR, risk ratio.

is quite high. ${ }^{17,19,20,28,29}$ In Southeast Asian countries such as Japan and Pakistan, this study found higher rates of incidence of cardiac arrest, by about three times. ${ }^{7,18}$ When compared to European countries, this study's results show a higher rate of incidence of cardiac arrest, by two to six times. ${ }^{8,12,32-34}$ There are dissimilarities in many factors, especially characteristics of the sample and selection of study samples. Some studies have included non-trauma patients in their study samples. In addition, the severity of patients and the type of injury in different areas are also different.

High rates of cardiac arrest as reported in this study are related to several factors. The data from this study show that patients with cardiac arrest were of ASA class more than 5 (67.2\%), which includes patients with cardiopulmonary disease (84.6\%). In such patients, $94.9 \%$ had been intubated, and on ventilator support prior to anesthesia, $47.3 \%$ of the patients were in shock from active blood loss prior to surgery and $20.8 \%$ had suffered cardiac arrest in the ER/ward during transfer to surgery. Such critical conditions need emergency surgery to save life, which limits the opportunity for anesthetists to evaluate and prepare the patient prior to anesthesia. Some patients may not be able to offer adequate nothing per oral (NPO) time prior to receiving anesthesia. In this study, $10.4 \%$ of the patients had had to undergo the rapid cricoid pressure intubation technique to prevent aspiration. These patients are at risk of developing aspiration pneumonia. ${ }^{35}$ Therefore, having an experienced anesthesiologist plays an important role in successfully intubating trauma patients both in the ER and in the operating room. In addition, vital organ anatomic sites of injuries have higher rates of cardiac arrest. This study found that patients with cardiac arrest were those who had had upper abdomen injury (45.8\%), brain injury $(21.4 \%)$, and chest injury (13.9\%). Therefore, the administration of anesthesia to trauma patients is a challenge for the anesthesia team as they must be able to care and solve any crises during anesthesia as well.

The multivariate regression analysis shows that this study had several significant factors associated with perioperative cardiac arrest in trauma patients, which included age $>65$ years, high ASA physical status, the anatomical site of surgery, preoperative cardiopulmonary comorbidity, personal history of alcoholism, and hemodynamic condition of instability with shock prior to receiving anesthesia.

This study shows statistical significance for age over 65 years as having double the risk of perioperative cardiac arrest compared to age between 13 and 34 years. This finding is consistent with the findings of the Thai anesthesia incident monitoring study (Thai AIMS) and other studies in Thailand. ${ }^{20,36}$ Upon comparing in the same setting, it was observed that elderly patient was a predictor of death after emergency surgery, as that factor increased the rate by $2.8-4.3$ times. ${ }^{30} \mathrm{As}$ for other studies such as those conducted in the USA, ${ }^{4,11,27,34}$ the $\mathrm{UK},{ }^{37}$ and Brazil,${ }^{38}$ they showed that elderly patient was a factor contributing to cardiac arrest during anesthesia, especially for patients who were more than 80 years of age. However, those studies had differences with regard to some characteristics of 
the population selected for entry, such as characteristic data, comorbidity disease, and surgery procedure.

The relatively high incidence of perioperative cardiac arrest in elderly patients observed in this study was caused by the elderly having cardiopulmonary comorbidities more than patients of other age. This study found that the percentage of trauma patients with cardiovascular diseases prior to anesthesia was $29.6 \%$, with $13.8 \%$ patients older than 65 years, and that the percentage of trauma patients with ASA class equal or more than 3 was $47.8 \%$. At the same time, $37.8 \%$ of the patients were in shock prior to anesthesia. A study conducted in a university hospital in Thailand found that elderly patients with cardiac disease are at high risk of cardiac arrest by about six times..$^{20}$ In addition, a study conducted in elderly patients in the USA found that patients who underwent cardiovascular surgery are very likely to be at high risk of perioperative cardiac arrest which is associated with increased age and also increased cardiopulmonary comorbidity. ${ }^{39}$ Standardized monitoring and intensive monitoring for anesthesia should be provided to monitor abnormalities and to promptly report warning signs to the anesthetist of an impending cardiac arrest. A recent study in this area found that monitoring, having a knowledgeable anesthesia team, and the availability of the team can help patients to increase survival rates. ${ }^{40}$

The ASA physical status class is one of the major factors affecting perioperative cardiac arrest. This study showed that patients with higher ASA class had a statistically significant increase exponentially in cardiac arrest from 4 to 21 times (ASA class 3-4 vs ASA class 5-6) compared to ASA class $1-2$. This is confirmed by a study conducted in Thailand which found that having a high ASA class increased the risk of cardiac arrest by five times. ${ }^{20}$ Other studies held in Asia have reported that, for higher ASA class, there is a 2-20 times more probability of suffering cardiac arrest. In developed countries such as Brazil, it has also been found that patients having ASA class of more than 3 is a relevant factor associated with cardiac arrest, ranging from 25 to 70 times. ${ }^{10}$

There exist differences in characteristics between trauma patients with high ASA class receiving anesthesia for emergency surgery and other patients in this area. In patients with major trauma with shock such as hypovolemic shock, many other causes are also involved, including anatomic site of injury, multiple injuries, and active blood loss in which most of them cannot administer fluids and blood immediately during surgery or prior to surgery. This study's data show that the patients had had the surgery performed on vital organs such as the upper intra-abdominal, intracranial, intrathoracic, and major vascular regions $(45.8 \%, 21.4 \%, 13.9 \%$, and $4.2 \%$, respectively). These surgical sites are one of the risk factors for cardiac arrest, making the risk about two to three times higher. Such patients who have high severity including a high ASA class, as well as patients in shock during transfer to surgery, need to have the cardiopulmonary crisis resolved prior to anesthesia. Among the patients in this study, $79.8 \%$ was intubated in the ER/ICU/ward before surgery, $47.3 \%$ of the patients were in shock, and $20.8 \%$ had suffered cardiac arrest prior to anesthesia. Confirmation with studies carried out in trauma patients showed that the seriousness of the patient and the probability of the patient suffering cardiac arrest was influenced by specific factors: the risk is particularly high in patients with severe blood loss, patients with hemodynamic instability, and patients with airway management problems. ${ }^{21}$ Therefore, trauma patients with ASA class 3 or higher is a challenge for the multidisciplinary teams, including the anesthetic team, operating room team, and surgery team, to create a system and to have training teams available to treat such patients.

In addition, the factor of surgical anatomic sites, especially, upper intra-abdominal injury, head injury, intrathoracic injury, and major vascular injury, was found to be associated with cardiac arrest two to three times more in this study than in other studies. This finding corresponds to the findings of recent studies in Thailand which reported that intrathoracic and upper abdominal surgeries had higher incidence of cardiac arrest by more than two times. ${ }^{20}$ Studies held in USA found that blunt trauma patients who underwent craniotomy and thoracotomy were at risk of suffering cardiac arrest more than three times. ${ }^{27}$ However, this study was conducted in patients with hemorrhagic shock. Data from the Nebraska Medical Center, Omaha, USA, from 1999 to 2009, showed that upper intra-abdominal injury and intrathoracic injury increased the risk of cardiac arrest by two- to fourfold.$^{11}$ Other studies carried out in USA showed that the number of fractured ribs was a factor significant for cardiac arrest. ${ }^{37}$ This corresponds to the results obtained in Brazilian traumatic patients with head injury, abdominal injury, thoracic injury, and vascular injury that their risk of cardiac arrest was higher by $5-32$ times. ${ }^{10,12}$ Furthermore, a study conducted in Singapore and the USA found that the severe complications suffered by most patients and the deaths were caused by falls and road traffic accidents (51.3\% and $39.5 \%$, respectively). It is in such accidents that the vital organs of the body are injured, including the head region and the thorax ( $45.40 \%$ and $28.05 \%$, respectively). ${ }^{6,11}$

The major accidents met with by these patients have been the cause of active blood loss. It affects the functioning of the 
vital organs of the body, especially the liver, heart, kidneys, and brain, resulting in cardiac arrest and death during surgery. Therefore, the administration of anesthesia to high-risk patients requires intensive monitoring of patient crisis and evaluation of abnormality of lap values that affect the function of the body quickly.

Additionally, preoperative cardiopulmonary comorbidity is a risk factor associated with increased possibility of cardiac arrest by approximately 1.5-fold, which is consistent with the findings of three studies in Thailand, which reported that cardiopulmonary comorbidity increased the risk of cardiac arrest by more than two times..$^{2,20,28}$ This is supported by a study carried out in trauma patients requiring ventilator support, which showed that the risk of cardiac arrest was seven times. ${ }^{1}$ Other studies were carried out in Brazil, ${ }^{8}$ Switzerland, ${ }^{41}$ and USA $; 3,4,37,42$ these studies found that heart disease and respiratory disorder increased the probability of suffering cardiac arrest by one to seven times. Furthermore, systematic reviews and case reports during 2005-2012 reported a positive correlation between respiratory and/or cardiovascular comorbidity and cardiac arrest. ${ }^{41,43}$ However, these studies were different in many characteristics including domain population, age of patients, anatomic site of surgery, etc.

Cardiopulmonary disorder due to cardiac complications during anesthesia can be caused by many factors including patients not receiving treatment or not receiving effective treatment because of urgent surgery, accident patients not having a history of the disease and the treatment, cases where the patient was unconscious or serious accidents where there was no relative to provide accurate information and incomplete personal history. At the same time, these patients would have also experienced serious complications such as severe blood loss, hemodynamic instability such as shock, and respiratory failure prior to anesthesia. A recent study in northern Thailand reported that among patients who suffered cardiac arrest within 24 hours of anesthesia, 96\% had had on endotracheal tube and ventilator support prior to anesthesia. Just this one factor increases the probability of cardiac arrest by 14.6 times. ${ }^{2}$ This study's data show that most patients with cardiac arrest had cardiopulmonary comorbidity (84.6\%). The percentage of patients in a state of shock prior to anesthesia was $47.3 \%$, and $79.8 \%$ had been ventilator supported. This study found that these factors were causes of cardiac arrest, increasing the probability by about 1.6 times. Furthermore, the percentage of patients who suffered cardiac arrest during resuscitation prior to anesthesia was $20.8 \%$. Therefore, the patient's history, information provided by relatives, and the transfer process between the multidisciplinary teams from the ER to the surgical setting and administration of anesthesia are important to help the patient effectually. Additionally, for the administration of anesthesia, there should be a system for consulting an expert quickly.

The incidence of shock in trauma patients prior to anesthesia is a major factor with regard to suffering cardiac arrest. This study's data presented that patients who received anesthesia but those who have not yet received surgical incision which causes hemodynamic instability are at an increased risk of cardiac arrest by about three to five times. Several studies support this study's result, such as two studies in Thailand ${ }^{2,30}$ and one study each in Japan, ${ }^{7}$ USA, ${ }^{3}$ and Brazil. ${ }^{8}$ They presented that patients with shock had a one- to twofold increase in the probability of suffering cardiac arrest. In the past decade, systematic reviews and case reports have reported about factors of correlation between patients with shock prior to anesthesia and increase in the rate of incidence of perioperative cardiac arrest. ${ }^{7,41}$ The anesthetic team must have awareness, and both defibrillator and drugs for resuscitation must be prepared. Furthermore, they should be aware that supplementary factors are a cause of cardiac arrest, including analytic reaction from allergy to drugs such as anesthetic drugs, antibiotics, and other drugs with histamine release. At the same time, during surgery, there may be major positive factors affecting cardiac arrest such as surgery which has active bleeding, anesthesia-induced hypotension, and underestimation of fluid or blood component replacement. The anesthesia team plays a direct role in the caring of these patients, including in the assessment of blood loss and proper administration of fluid and blood components. According to recent studies, it is confirmed that having an expert anesthesia team holds the key to helping patients survive. ${ }^{44}$ Thus, the caring process for trauma patients requires teamwork and coordination between multidisciplinary teams, which will be able to help patients effectively, and this would significantly reduce the time spent on the duration from the time the patient arrives until the start of incision..$^{45}$

Other factors related to cardiac arrest in trauma patients include drinking alcohol. This study found that patients' having a history of drinking alcohol is a factor that causes a fivefold increase in the probability of cardiac arrest. This is confirmed by a study in patients with orthopedic trauma in the USA in which it was found that in the case of patients who had had accidents in which alcohol drinking was involved, there was a fourfold increase in the probability of cardiac arrest. ${ }^{4}$ Consistent with many studies, especially in developing countries such as Cambodia, it was seen that $40 \%$ of traumatic brain injuries happen during the holidays, and $74 \%$ are caused by road traffic accidents, especially because of riding motorcycles 
rashly, drinking alcohol, and failure to comply with traffic laws. ${ }^{46} \mathrm{~A}$ study in India reported that driving while under the influence of alcohol causes an increase in threat to life by 1.7 times. ${ }^{14}$ In Norway, an investigation presented that the risk of meeting with a traffic accident is greatly increased among drivers who test positive for alcohol drinking. ${ }^{15}$ In Thailand, it has been found that drinking causes an increase in motor accidents. It is also a major problem and a threat to life. ${ }^{16}$

The high incidence rate of cardiac arrest in trauma patients with alcohol addiction observed in this study may be because of several factors, especially in northern Thailand, as Chiang Mai province is a tourist city, a city of both Thai people and foreigners. The country has many consecutive holidays including holidays during local festivals such as the New Year Festival, Songkran Festival, Loy Krathong Festival, Chinese New Year Festival, regular holidays, etc. These festivals are promoted so that the maximum number of people come to Chiang Mai, especially by cars and motorcycles or big bikes; these visitors may also be celebrating their holidays by drinking alcohol while driving, and some drivers may not be wearing helmets or safety belts. Therefore, prevention of disastrous events such as accidents is beyond the control and field of anesthesia officials. The findings of this study should be presented to the authorities in order that a public health policy is formulated so as to create a strategy that works toward a "promotion of health better than repair of health" policy. The agency should have a policy, or enforce the law seriously, especially with regard to sale of alcohol to the youth, sale of alcohol during festivals, drunken driving, and wearing a helmet and wearing the seat belt during driving. These strategies should reduce the number of serious accidents, and, in turn, reduce the rates of incidence of cardiac arrest and death during surgery.

This retrospective study had limitations in the analysis of the risk factors. At the same time, during the time of data collection, although the researcher's focus was on the accuracy of the data, the documents of the data were edited prior to being entered in the hospital database through clarification of the variable for accuracy by both the anesthesiologist and the nurse anesthetist. However, some significant parameters were missing, and the research assistant did not understand the accurate meaning of some variables in the hospital database. Additionally, the findings of this study cannot be generalized to other areas including emergency departments, ICUs, and trauma centers.

\section{Conclusion}

The incidence of perioperative cardiac arrest in trauma patients receiving anesthesia for emergency surgery was very high and correlated with patient's factors, especially with regard to elderly patients and cardiopulmonary comorbidities; patients having a history of alcohol consumption; increased ASA physical status; hemodynamic instability with shock prior to surgery; and sites of surgery including brain, thorax, abdomen, and the major vascular region. Anesthesiologists and surgeon's teams should have a warning system and a well-equipped track to manage the high-risk group of surgical trauma patients.

\section{Acknowledgments}

This study has been supported by a grant from Chiang Mai University. The authors wish to thank the director of Maharaj Nakorn Chiang Mai Hospital, Department of Anesthesiology, for providing the data. The abstract of this paper was presented at the Singapore Trauma and Acute Care Conference 2018 as only a poster presentation with our interim findings.

\section{Disclosure}

The authors report no conflicts of interest in this work.

\section{References}

1. Chau-In W. Airway Management of the Trauma Victims. Srinagarind Med J. 2006;21(1):59-76.

2. Siriphuwanun V, Punjasawadwong Y, Lapisatepun W, Charuluxananan $\mathrm{S}$, Uerpairojkit K. Incidence of and factors associated with perioperative cardiac arrest within 24 hours of anesthesia for emergency surgery. Risk Manag Healthc Policy. 2014;7:155-162.

3. Goswami S, Brady JE, Jordan DA, Li G. Intraoperative cardiac arrests in adults undergoing noncardiac surgery: incidence, risk factors, and survival outcome. Anesthesiology. 2012;117(5):1018-1026.

4. Dodd AC, Lakomkin N, Sathiyakumar V, Obremskey WT, Sethi MK. Do orthopaedic trauma patients develop higher rates of cardiac complications? An analysis of 56,000 patients. Eur J Trauma Emerg Surg. 2017;43(3):329-336.

5. Chandran A, Sousa TR, Guo Y, Bishai D, Pechansky F; Vida No Transito Evaluation Team. Road traffic deaths in Brazil: rising trends in pedestrian and motorcycle occupant deaths. Traffic Inj Prev. 2012;13(Suppl 1):11-16.

6. Wui LW, Shaun GE, Ramalingam G, Wai KM. Epidemiology of trauma in an acute care hospital in Singapore. J Emerg Trauma Shock. 2014;7(3):174-179.

7. Irita K, Kawashima Y, Iwao Y, et al. Annual mortality and morbidity in operating rooms during 2002 and summary of morbidity and mortality between 1999 and 2002 in Japan: a brief review. Masui. 2004;53(3):320-335.

8. Braz LG, Módolo NS, do Nascimento P Jr, et al. Perioperative cardiac arrest: a study of 53,718 anaesthetics over $9 \mathrm{yr}$ from a Brazilian teaching hospital. Br J Anaesth. 2006;96(5):569-575.

9. Nunes JC, Braz JR, Oliveira TS, de Carvalho LR, Castiglia YM, Braz LG. Intraoperative and anesthesia-related cardiac arrest and its mortality in older patients: a 15-year survey in a tertiary teaching hospital. PLoS One. 2014;9(8):e104041.

10. Carlucci MT, Braz JR, do Nascimento P Jr, de Carvalho LR, Castiglia YM, Braz LG. Intraoperative cardiac arrest and mortality in trauma patients. A 14-yr survey from a Brazilian tertiary teaching hospital. PLoS One. 2014;9(2):e90125.

11. Ellis SJ, Newland MC, Simonson JA, et al. Anesthesia-related cardiac arrest. Anesthesiology. 2014;120(4):829-838. 
12. Pignaton W, Braz JR, Kusano PS, et al. Perioperative and AnesthesiaRelated Mortality: An 8-Year Observational Survey From a Tertiary Teaching Hospital. Medicine (Baltimore). 2016;95(2):e2208.

13. Ferguson RW, Henderson SJ, Jung P. Road traffic injuries in Peace Corps Volunteers, 1996-2014. Inj Prev. 2017;23(2):75-80.

14. Esser MB, Wadhwaniya S, Gupta S, et al. Characteristics associated with alcohol consumption among emergency department patients presenting with road traffic injuries in Hyderabad, India. Injury. 2016;47(1):160-165.

15. Bogstrand ST, Gjerde H, Normann PT, Rossow I, Ekeberg Ø. Alcohol, psychoactive substances and non-fatal road traffic accidents--a casecontrol study. BMC Public Health. 2012;12:734.

16. Woratanarat $P$, Ingsathit A, Suriyawongpaisal P, et al. Alcohol, illicit and non-illicit psychoactive drug use and road traffic injury in Thailand: a case-control study. Accid Anal Prev. 2009;41(3):651-657.

17. Suraseranivongse S, Chawaruechai T, Saengsung P, Komoltri C. Outcome of cardiopulmonary resuscitation in a 2300-bed hospital in a developing country. Resuscitation. 2006;71(2):188-193.

18. Ahmed A, Ali M, Khan EA, Khan MU. An audit of perioperative cardiac arrests in a Southeast Asian university teaching hospital over 15 years. Anaesth Intensive Care. 2008;36(5):710-716.

19. Charuluxananan S, Suraseranivongse S, Jantorn P, et al. Multicentered study of model of anesthesia related adverse events in Thailand by incident report (The Thai Anesthesia Incidents Monitoring Study): results. J Med Assoc Thai. 2008;91(7):1011-1019.

20. Tamdee D, Charuluxananan S, Punjasawadwong Y, et al. Factors related to 24-hour perioperative cardiac arrest in geriatric patients in a Thai university hospital. J Med Assoc Thai. 2009;92(2):198-207.

21. Bernhard M, Matthes G, Kanz KG, et al. Notfallnarkose, Atemwegsmanagement und Beatmung beim Polytrauma. Hintergrund und Kernaussagen der interdisziplinären S3-Leitlinie Polytrauma. [Emergency anesthesia, airway management and ventilation in major trauma. Background and key messages of the interdisciplinary S3 guidelines for major trauma patients]. Anaesthesist. 2011;60(11):1027-1040. German.

22. Mosquera VX, Marini M, Muñiz J, et al. Blunt traumatic aortic injuries of the ascending aorta and aortic arch: a clinical multicentre study. Injury. 2013;44(9):1191-1197.

23. Clarke DL, Quazi MA, Reddy K, Thomson SR. Emergency operation for penetrating thoracic trauma in a metropolitan surgical service in South Africa. J Thorac Cardiovasc Surg. 2011;142(3):563-568.

24. Duane TM, Rao IR, Aboutanos MB, Wolfe LG, Malhotra AK. Are trauma patients better off in a trauma ICU? J Emerg Trauma Shock. 2008;1(2):74-77.

25. Toledo FO, Gonzalez MM, Sebbag I, et al. Outcomes of patients with trauma and intraoperative cardiac arrest. Resuscitation. 2013;84(5): 635-638.

26. Ahmed A, Ali M, Khan M, Khan F. Perioperative cardiac arrests in children at a university teaching hospital of a developing country over 15 years. Paediatr Anaesth. 2009;19(6):581-586.

27. Hwabejire JO, Nembhard CE, Oyetunji TA, et al. Age-related mortality in blunt traumatic hemorrhagic shock: the killers and the life savers. J Surg Res. 2017;213:199-206.

28. Pipanmekaporn T, Bunchungmonkol N, Chuaratanaphong S, Punjasawadwong Y, Saringcaringkul A, Sawaddiruk P. Perioperative mortality and risk factors in cardiac surgery, a review of 3,822 cases at the Northern Cardiac Center. Chiang Mai Med J. 2009;48(1):15-24. Available from http://www.med.cmu.ac.th/secret/edserv/journal/ fulltext/02_Peroperative\%20mortality\%20and\%20risk\%20factor_Tanyong.pdf. Accessed October 08, 2018.
29. Bunchungmongkol N, Punjasawadwong Y, Chumpathong S, et al. Anesthesia-related cardiac arrest in children: the Thai Anesthesia Incidents Study (THAI Study). JMed Assoc Thai. 2009;92(4):523-530.

30. Siriphuwanun V, Punjasawadwong Y, Lapisatepun W, Charuluxananan S, Uerpairojkit K. Prognostic factors for death and survival with or without complications in cardiac arrest patients receiving CPR within 24 hours of anesthesia for emergency surgery. Risk Manag Healthc Policy. 2014;7:199-210.

31. Charuluxananan S, Punjasawadwong Y, Suraseranivongse S, et al. The Thai Anesthesia Incidents Study (THAI Study) of anesthetic outcomes: II. Anesthetic profiles and adverse events. J Med Assoc Thai. 2005;88(Suppl 7):S14-S29.

32. Vane MF, do Prado Nuzzi RX, Aranha GF, et al. Perioperative cardiac arrest: an evolutionary analysis of the intra-operative cardiac arrest incidence in tertiary centers in Brazil. Rev Bras Anestesiol. 2016;66(2):176-182.

33. Sebbag I, Carmona MJ, Gonzalez MM, et al. Frequency of intraoperative cardiac arrest and medium-term survival. Sao Paulo Med J. 2013;131(5):309-314.

34. Nunnally ME, O'Connor MF, Kordylewski H, Westlake B, Dutton RP. The incidence and risk factors for perioperative cardiac arrest observed in the national anesthesia clinical outcomes registry. Anesth Analg. 2015;120(2):364-370.

35. Klanarong S, Suksompong S, Hintong T, Chau-In W, Jantorn P, Werawatganon T. Perioperative pulmonary aspiration: an analysis of 28 reports from the Thai Anesthesia Incident Monitoring Study (Thai AIMS). J Med Assoc Thai. 2011;94(4):457-164.

36. Tuchinda L, Sukchareon I, Kusumaphanyo C, Suratsunya T, Hintong T, Thienthong S. The Thai Anesthesia Incident Monitoring Study (Thai AIMS): an analysis of perioperative complication in geriatric patients. J Med Assoc Thai. 2010;93(6):698-707.

37. Battle CE, Hutchings H, Evans PA. Expert opinion of the risk factors for morbidity and mortality in blunt chest wall trauma: results of a national postal questionnaire survey of Emergency Departments in the United Kingdom. Injury. 2013;44(1):56-59.

38. Braghiroli KS, Braz JRC, Rocha B, et al. Perioperative and anesthesiarelated cardiac arrests in geriatric patients: a systematic review using meta-regression analysis. Sci Rep. 2017;7(1):2622.

39. Silvay G, Castillo JG, Chikwe J, Flynn B, Filsoufi F. Cardiac anesthesia and surgery in geriatric patients. Semin Cardiothorac Vasc Anesth. 2008;12(1):18-28.

40. Siriphuwanun V, Punjasawadwong Y, Lapisatepun W, Charuluxananan S, Uerpairojkit K, Patumanond J. The initial success rate of cardiopulmonary resuscitation and its associated factors in patients with cardiac arrest within 24 hours after anesthesia for an emergency surgery. Risk Manag Healthc Policy. 2014;7:65-76.

41. Zuercher M, Ummenhofer W. Cardiac arrest during anesthesia. Curr Opin Crit Care. 2008;14(3):269-274.

42. Battle CE, Hutchings H, Evans PA. Risk factors that predict mortality in patients with blunt chest wall trauma: a systematic review and metaanalysis. Injury. 2012;43(1):8-17.

43. Gonzalez LP, Pignaton W, Kusano PS, Módolo NS, Braz JR, Braz LG. Anesthesia-related mortality in pediatric patients: a systematic review. Clinics (Sao Paulo). 2012;67(4):381-387.

44. Walsh SR, Bhutta H, Tang TY, et al. Anaesthetic specialisation leads to improved early- and medium-term survival following major vascular surgery. Eur J Vasc Endovasc Surg. 2010;39(6):719-725.

45. Capella J, Smith S, Philp A, et al. Teamwork training improves the clinical care of trauma patients. J Surg Educ. 2010;67(6):439-443.

46. Peeters S, Blaine C, Vycheth I, Nang S, Vuthy D, Park KB. Epidemiology of Traumatic Brain Injuries at a Major Government Hospital in Cambodia. World Neurosurg. 2017;97:580-589. 


\section{Publish your work in this journal}

Risk Management and Healthcare Policy is an international, peer-reviewed open access journal focusing on all aspects of public health, policy, and preventative measures to promote good health and improve morbidity and mortality in the population. The journal welcomes submitted papers covering original research, basic science, clinical and epidemiological

Submit your manuscript here: https://www.dovepress.com/risk-management-and-healthcare-policy-journal

studies, reviews and evaluations, guidelines, expert opinion and commentary, case reports and extended reports. The manuscript management system is completely online and includes a very quick and fair peerreview system, which is all easy to use. Visit http://www.dovepress.com/ testimonials.php to read real quotes from published authors. 